\title{
Correlation between anthropometric indices at birth and developmental delay in children aged 4-60 months in Isfahan, Iran
}

This article was published in the following Dove Press journal:

International Journal of General Medicine

17 August 2012

Number of times this article has been viewed

\section{S Amir Ali Akbari \\ $S$ Montazeri² \\ F Torabi $^{3}$ \\ S Amiri ${ }^{3}$ \\ F Soleimani $^{4}$ \\ H Alavi Majd ${ }^{5}$}

'Department of Midwifery, Faculty of Nursing and Midwifery, Shahid Beheshti University of Medical Sciences, Tehran, Iran; ${ }^{2}$ Reproductive Health, British Columbia, Canada; ${ }^{3}$ Faculty of Nursing and Midwifery, Shahid Beheshti, University of Medical Sciences, Tehran, Iran; ${ }^{4}$ Pediatric Neurorehabilitation Research Center, University of Social Welfare and Rehabilitation Sciences, Tehran, Iran; ${ }^{5}$ Department of Biostatistics, Faculty of Paramedical, Shahid Beheshti University of Medical Sciences, Tehran, Iran
Correspondence: Shabnam Montazeri Reproductive Health, 4440 Hastings Street, Burnaby, British Columbia, Canada

Tel +l 7788954642

Email shabnam_montazeri@yahoo.com
Background: Advances in medical knowledge and treatment modalities have resulted in an increased survival rate for high-risk infants. This increased number of survivors enables study of the future development of these children. Other than infection and trauma, developmental and behavioral problems are the most common medical problems among such children. This study sought correlations between anthropometric indices at birth and developmental delay in children aged 4-60 months who visited health service centers affiliated with the Isfahan University of Medical Sciences in 2010.

Methods: In this descriptive, correlational study, 401 children aged 4-60 months and visiting health service centers were selected using a multistage method. Anthropometric indices at birth were collected from their health care records, and developmental status was measured using the Ages and Stages Questionnaire, the validity (0.84) and reliability (0.94) of which were obtained from a previous study.

Results: The mean age of the children in the normal group was $17.33 \pm 13.18$ months and that in the developmental delay group was $29.92 \pm 19.19$ months. Most children in the normal group were female $(56 \%)$ and in the developmental delay group were male (55.2\%). No correlation was found between height and head circumference at birth and developmental delay. However, the birth weight of children with developmental delay was four times lower than that of children with normal development ( $P=0.004$, odds ratio 4).

Conclusion: Birth weight and male gender were factors that strongly correlated with developmental delay in this study.

Keywords: anthropometric indices, developmental delay, children

\section{Introduction}

Improvements in medical science have resulted in increased survival of vulnerable and high-risk infants, enabling further study on the future development of these children. However, although infant mortality has been reduced, these children may be more biologically vulnerable than other children. In the last two decades, because of improvements in health status and increased use of vaccinations and antibiotics, mortality and complications from infectious diseases have been reduced in children. However, due to increased survival of infants with birth weight $<1500 \mathrm{~g}$ and fetal age $<30$ weeks, along with development and implementation of infertility treatments, the frequency of developmental disorders have increased significantly. ${ }^{1}$

Developmental delay is a term used for children who lack developmental features and skills that would be expected of children their age. ${ }^{2}$ After infection and trauma, developmental and behavioral disorders are the most common problems in 
pediatric medicine. Approximately $15 \%-18 \%$ of children in the US suffer from developmental or behavioral disabilities. However, because these problems often remain unaddressed, most of these disorders are either unidentified or untreated until the children have reached school age. This lack of diagnosis and treatment results in several complications that threaten the health and development of a community. In fact, many delays in growth and development can be traced back to the prenatal period. ${ }^{3}$ The main cause or causes of developmental disabilities are often unknown, but biological factors, complications of pregnancy, and environmental factors are some of the possibilities. ${ }^{4}$

Human resources are fundamental to the development of society. The most important foundation for this development is the children of the next generation. Children afflicted by developmental delay have numerous problems, so early diagnosis and timely referral are very important in facilitating maximum benefit for children with developmental disabilities, their families, and ultimately society as a whole. ${ }^{5}$ Monitoring and screening child development to detect problems associated with delay at each child visit, especially the first, is thus very important. Developmental evaluation is required in five areas, ie, motor development (gross and fine motor skills), cognitive, emotional, and communication development, and perception (hearing, speech, and visual motor skills). ${ }^{3}$

The results of studies of anthropometric indices at birth differ with regard to the relationships of these indices with developmental status. Glasson and Petterson reported no correlation between anthropometric indices and cognitive developmental disorders. ${ }^{6}$ On the other hand, Hediger et al reported a significant relationship between low birth weight and sociophysical development. ${ }^{7}$ Piek et al suggested a significant relationship between low birth weight and fine motor skills in children of school age. ${ }^{8}$ To reconcile these contradictory results, this study aimed to determine correlations between anthropometric indices at birth and developmental delay in children aged 4-6 months who were referred to health centers affiliated with the Isfahan University of Medical Sciences in 2010.

\section{Materials and methods}

This descriptive correlational study included 401 Iranian children aged 4-60 months, with complete records, no obvious congenital anomalies, and living with both parents. Their recorded Apgar scores were $\leq 4$. They were not hospitalized after birth for reasons other than midwifery (including accidents and trauma).
Using a cluster probability sampling method, 13 health care centers were selected from throughout Isfahan. Next, the children were selected from each cluster on the basis of number of clients, and sampling days were selected randomly. After introducing and explaining the research objectives to the parents and obtaining their verbal consent, sampling began. The subjects were free to accept or reject participation in the study and they could withdraw if they wished. After completing the study, the results were given to the heads of the research centers.

Once parental consent had been obtained, the developmental status of the children was measured in five areas, ie, motor (gross and fine motor skills), cognitive, emotional, and communication development, and perceptual skills. Anthropometric data at birth were collected from the children's health records.

Problem-solving was assessed using the Ages and Stages Questionnaire. This questionnaire has been used in many studies. ${ }^{9-12}$ Adaptation and standardization of this questionnaire in Iran was performed from the years 2002 to 2007 under the supervision of the Iranian Ministry of Health and Medical Education, United Nations Childrens Fund, International Council for the Education of Exceptional Children, Office of Population and Family Health, and Institute for Exceptional Children. The validity and reliability of the questionnaire have been established as 0.84 and 0.94 , respectively, and its ability to determine developmental disorders is reported as $>96 \%{ }^{1}$

After children with developmental delay had been identified, they were referred to medical centers to confirm that the diagnosis was correct. The content validity method was used for validation of the checklist used for collecting birth-related anthropometric data from health records. The reliability of the checklist was measured using the simultaneous measurement method. In this study, confounding factors such as socioeconomic status (a variable combination of five variables, ie, parental education level, housing status, area of house infrastructure, and monthly income $P>0.05)$, maternal age $(P=0.41)$, birth order and number of children $(P=0.51)$, child gender $(P=0.07)$, and maternal employment $(P=0.8)$ in the two groups were matched.

The data were analyzed using SPSS software version 18 (SPSS Inc, Chicago, IL). In this study, statistical analyses were performed using the independent $t$-test for quantitative variables (correlation between development and length or head circumference at birth), the $\chi^{2}$ test for qualitative variables (correlation between each area of development 
and birth weight), and the Mann-Whitney $U$ test for ranking variables (correlation between development and birth weight). Odds ratios and logistic regression models were also used for data analysis.

\section{Results}

The correlation between children's development and head circumference at birth and that between development and birth length are shown in Tables 1 and 2. Mean age was $17.33 \pm 13.18$ months in the normal development group and $29.92 \pm 19.19$ months in the developmental delay group. Of the children whose records were evaluated in this study, $5.4 \%$ were preterm at the time of delivery ( $<37$ weeks) and $94.6 \%$ were born at $37-40$ weeks' gestation. Of the children in the developmental delay group, $10.5 \%$ were boys and $8.2 \%$ were girls, indicating that the delay was more prevalent in boys than in girls. In the logistic model, male gender showed a significant correlation with developmental delay $(P<0.05)$.

The results show that the prevalence of developmental delay was $18.7 \%$ in children who visited the health centers included in this study. The highest prevalence of developmental delay was in the area of fine motor skills (7.2\%; 95\% confidence interval [CI] 3.9-10.5) and the lowest was in the area of sociopersonal skills $(1.7 \%$; $95 \%$ CI 0.5-2.9).

The correlation between development and birth weight in the children included in this study is shown in Tables 3 and 4. The results show that developmental delay was observed in 61 children with normal birth weight and 41 children with low birth weight. In addition, 308 children with normal birth weight and 18 children with low birth weight had normal development. The Mann-Whitney $U$ test was used to evaluate the developmental status differences between groups. Significant differences were observed between groups in the results of this test $(P=0.000, Z=-3.81)$.

The results of the $\chi^{2}$ test revealed significant differences between children with normal and low birth weight.

Table I Correlation between development and head circumference at birth in children referred to health centers affiliated with Isfahan University of Medical Sciences in 2010

\begin{tabular}{lll}
\hline $\begin{array}{l}\text { Head } \\
\text { circumference }\end{array}$ & $\begin{array}{l}\text { Normal } \\
\text { development } \\
\mathbf{n}=\mathbf{3 2 6}\end{array}$ & $\begin{array}{l}\text { Developmental } \\
\text { delay } \\
\mathbf{n}=\mathbf{7 5}\end{array}$ \\
\hline Mean & 34.67 & 34.35 \\
Standard deviation & $\mathrm{I} .4$ & 1.7 \\
Total & $40 \mathrm{I}$ & \\
Statistical test & $\mathrm{T}=-\mathrm{I} / 7 \mathrm{I}$ & $P=0 / 09$ \\
\hline
\end{tabular}

Table 2 Correlation between development and length at birth in children referred to health centers affiliated with Isfahan University of Medical Sciences in 2010

\begin{tabular}{lll}
\hline Birth length & $\begin{array}{l}\text { Normal } \\
\text { development } \\
\mathbf{n}=\mathbf{3 2 6}\end{array}$ & $\begin{array}{l}\text { Developmental } \\
\text { delay } \\
\mathbf{n}=\mathbf{7 5}\end{array}$ \\
\hline Mean & 49.6 & 49 \\
Standard deviation & 2.4 & 2.3 \\
Total & $40 \mathrm{I}$ & \\
Statistical test & $\mathrm{T}=-1 / 7$ & $P=0 / 08$ \\
\hline
\end{tabular}

Developmental delay in the low-birth weight group was significantly higher $(P<0.0001)$. Entering the anthropometric data at birth into the logistic regression model show that children with developmental delay were four times more likely to have low birth weight than children with normal development (weight $<2500 \mathrm{~g}, P=0.04$, odds ratio 4). A significant correlation was observed between low birth weight and developmental delay in the areas of gross motor skills, problem-solving, and sociopersonal skills. No significant correlation was found between head circumference and developmental delay, or birth length and developmental delay.

\section{Discussion}

The results show that head circumference and birth length have no significant correlation with developmental delay, while birth weight is significantly correlated with developmental delay. In this study sample, the prevalence of low birth weight was $8 \%$, which was reported as $7.5 \%$ and $7.2 \%$ in the US and Iran in 2009. ${ }^{1}$ Soleimany et al showed this prevalence to be $22.9 \%$, suggesting that more attention to health care services is needed in underserved areas. ${ }^{13}$

Kerstjens et al found significant differences between low birth weight and premature infants born at $<32$ weeks' gestational age and children in a control group in all developmental areas. They also showed that birth weight and prematurity increased the chance of developmental delay

Table 3 Correlation between development and birth weight in children referred to health centers affiliated with the Isfahan University of Medical Sciences in 2010

\begin{tabular}{lllll}
\hline $\begin{array}{l}\text { Birth weight } \\
\text { (g) }\end{array}$ & $\begin{array}{l}\text { Developmental } \\
\text { delay }\end{array}$ & \multicolumn{2}{l}{$\begin{array}{l}\text { Normal } \\
\text { development }\end{array}$} \\
\hline$>2500$ & $6 \mathrm{I}$ & 16.5 & 308 & 83.5 \\
I50I-2500 & $\mathrm{II}$ & 40.7 & $\mathrm{I}$ & 59.3 \\
I00I-I500 & 3 & 75 & $\mathrm{I}$ & 25 \\
$<\mathrm{I000}$ & 0 & 0 & $\mathrm{I}$ & 100 \\
Total & 75 & 18.7 & 326 & 81.3 \\
\hline Note: Mann-Whitney $U$ test: $P<0.000$. & & &
\end{tabular}


Table 4 Correlation between development in various areas with birth weight in children referred to health centers affiliated with the Isfahan University of Medical Sciences in 2010

\begin{tabular}{|c|c|c|c|c|c|}
\hline \multirow[t]{2}{*}{ Developmental delay } & \multicolumn{2}{|c|}{ Low birth weight } & \multicolumn{2}{|c|}{ Normal birth weight } & \multirow{2}{*}{$\begin{array}{l}\text { Statistical } \\
\text { results }\end{array}$} \\
\hline & $\mathbf{n}$ & Percentage & $n$ & Percentage & \\
\hline Communication & 3 & 9.4 & 19 & 5.1 & $P=0.2$ \\
\hline \multirow[t]{2}{*}{ Gross motor } & 4 & 12.5 & 12 & 3.3 & $P=0.03$ \\
\hline & & & & & $\mathrm{OR}=4.3$ \\
\hline Fine motor & 5 & 15.6 & 24 & 6.5 & $P=0.07$ \\
\hline \multirow[t]{2}{*}{ Problem solving } & 5 & 15.6 & 17 & 4.6 & $P=0.02$ \\
\hline & & & & & $\mathrm{OR}=3.8$ \\
\hline \multirow[t]{2}{*}{ Sociopersonal } & 2 & 6.3 & 5 & 1.4 & $P=0.04$ \\
\hline & & & & & $\mathrm{OR}=4.8$ \\
\hline
\end{tabular}

Abbreviation: OR, odds ratio.

from 1.5 to 4.9 times. ${ }^{14}$ Hediger et al also found low birth weight to be relevant to developmental delay in social and motor areas. ${ }^{7}$ On the other hand, Glasson and Petterson found no significant differences in birth weight between children with impaired cognitive development and those in a control group. ${ }^{6}$ Soleimany et al ${ }^{1,15}$ found an association between low birth weight and motor developmental delay, which was later confirmed by Sajedi and Alizadeh. ${ }^{16}$ The same results were also reported by Piek et al. ${ }^{8}$

In this study, male gender correlated significantly with developmental delay. Hediger et al found a significantly higher incidence of developmental delay in social and motor areas among boys compared with girls. ${ }^{7}$ Kerstjens et al identified an incidence of developmental delay that was 1.5-4.7 times higher in boys than in girls. ${ }^{14}$ On the other hand, Piek et al showed no effect of gender on rate of development in children. ${ }^{8}$ Lin et al suggested that developmental delay was twice as high in boys as in girls. ${ }^{5}$ Chakrabarti and Fombonne found that the prevalence of pervasive developmental disorders was significantly higher in boys than in girls. ${ }^{17}$

In contrast with these studies, the study by Soleimani et al found no significant correlation between gender and developmental delay, ${ }^{15}$ which is similar to the results found by Sajedy and Alizadeh. ${ }^{16}$ Although gender may not correlate significantly with developmental delay, significant correlations have been found in other areas, such as sociopersonal skills and communication. The results of this study show significant correlations in these areas.

Golombok et al found no effect of low birth weight on emotional and behavioral development, but weaker performance in terms of language developmental skills in the children examined in their study. ${ }^{18}$ In contrast, Piek et al found a significant relationship between low birth weight and fine motor skill development at school age $(\mathrm{r}=0.4$, $P=0.022)^{8}$
Glasson and Petterson analyzed the relationship between anthropometric indices (head, weight, and head circumference at birth) and autism, and found no significant associations. ${ }^{6}$ Hediger et al identified low birth weight as the most important prenatal predictor of development in girls; however, in boys, both low birth weight and gestational age were associated with social and physical development. ${ }^{7}$

In general, several factors leading to intrauterine growth retardation can cause problems during infancy. These problems include low blood sugar, asphyxia, polycythemia, hypothermia, and dysmorphology. Further, infants with low birth weight and associated complications are more frequently admitted to neonatal intensive care units, and are more likely to manifest developmental disorders in childhood. ${ }^{19}$

\section{Acknowledgments}

The authors sincerely thank all the health centers and academic units who participated in this study.

\section{Disclosure}

The authors report no conflicts of interest in this work.

\section{References}

1. Soleimani F, Vameghi R, Dadkhah A. High risk infants referred to health-care centers in North and East of Tehran and risk factors of motor developmental delay. Hakim Res J. 2009;12(2):11-18.

2. Baker RC. Pediatric Primary Care: Well-Child Care. Philadelphia, PA: Lippincott Williams and Wilkins Publishers; 2001.

3. Behrman RE, Kliegman RM, Jenson HB. Nelson Textbook of Pediatrics. Volume 1. 17th ed. Philadelphia, PA: Saunders; 2004.

4. Fox JA. Primary Health Care of Children. St Louis, MO: Mosby; 1997.

5. Lin JD, Yen CF, Wu JL, Kang SW. The administrative population report on children with developmental delays in Taiwan, 2003 through 2007. Res Dev Disabil. 2009;30(2):353-358.

6. Glasson EJ, Petterson B. Perinatal factors and development of autism. Arch Gen Psychiatry. 2007;61(2):618-627.

7. Hediger ML, Overpeck MD, Ruan WJ, Troendle JF. Birthweight and gestational age effects on motor and social development. Paediatr Perinat Epidemiol. 2002;16(6):33-46. 
8. Piek JP, Dawson L, Smith LM, Gasson N. The role of early fine and gross motor development on later motor and cognitive ability. Hum Mov Sci. 2008;27(5):668-681.

9. Limbos MM, Joyce DP. Comparison of the ASQ and PEDS in screening for developmental delay in children presenting for primary care. $J \mathrm{Dev}$ Behav Pediatr. 2011;32(7):499-511.

10. Mackrides PS, Ryherd SJ. Screening for developmental delay. Am Fam Physician. 2011;84(5):544-549.

11. Jodkowska M, Oblacińska A, Mikiel-Kostyra K, Tabak I. Screening for developmental disorders of infants and young children in the primary care clinics - is there a need for standardized tools implementation. Med Wieku Rozwoj. 2010;14(2):108-112. Polish.

12. Simard MN, Luu TM, Gosselin J. Concurrent validity of ages and stages questionnaires in preterm infants. Pediatrics. 2012;130(1):e108-e114.

13. Soleimani ZL, Danesh A, Basri N, Abaszadeh A, Arab M. Assessment of high risk pregnancy in Bam Mahdieh maternity hospital. Shahrekord Uni Med Sci. 2001;6(2):67-73. Persian.
14. Kerstjens JM, Bos AF, Vergert EMJ, Meer G, Butcher PR, Reijneveld SA. Support for global feasibility of the age and stages questionnaire as developmental screener. Early Hum Dev. 2009;85(7):443-447.

15. Soleimani F, Khoshbin E, Shams S. Report of motor developmental delay screening of infants (4-18 months old) of Karaj City. Quarterly Journal of Rehabilitation. 2001;2(3):22-28. Persian.

16. Sajedy F, Alizadeh V. The incidence of motor developmental delay in high risk infants and effective risk factors in developing of it. Quarterly Journal of Rehabilitation. 2008;5(4):7-12. Persian.

17. Chakrabarti S, Fombonne E. Pervasive developmental disorders in preschool children. Am J Psychiatry. 2005;162(6):1133-1141.

18. Golombok S, Olivennes F, Ramogida C, Rust J, Freeman T. Parenting and the psychological development of a representative sample of triplets conceived by assisted reproduction. Hum Reprod. 2007;22(11) 2896-2902.

19. Salt A, Redshaw M. Neurodevelopmental follow up after preterm birth. Early Hum Dev. 2006;82(3):185-197.
International Journal of General Medicine

\section{Publish your work in this journal}

The International Journal of General Medicine is an international, peer-reviewed open-access journal that focuses on general and internal medicine, pathogenesis, epidemiology, diagnosis, monitoring and treatment protocols. The journal is characterized by the rapid reporting of reviews, original research and clinical studies across all disease areas.

\section{Dovepress}

A key focus is the elucidation of disease processes and management protocols resulting in improved outcomes for the patient.The manuscript management system is completely online and includes a very quick and fair peer-review system. Visit http://www.dovepress.com/ testimonials.php to read real quotes from published authors.

Submit your manuscript here: http://www.dovepress.com/international-journal-of-general-medicine-journal 